\title{
Future Directions for Power System Interconnection from Korea's Perspective
}

\author{
Jae Young Yoon*, Sunghwan Song
}

Korean Electrotechnology Research Institute, Uiwang, Kyunggido, Republic of Korea

\begin{abstract}
The power system interconnection between Northeast Asian countries has been discussed since 2000 but has not been realized to date due to various obstacles. This paper specifies the expected future energy policy, long-term energy supply plan, and necessity of power interconnection from the Korean viewpoint, including the climate change agreement. There are very many interconnection scenarios presented by various institutes in NEA countries now. These studies contain the overall preliminary feasibility results but do not consider the environmental effects, energy security, and market reforms. Do these existing studies show how we could interconnect specific countries? This paper discusses the trading potentials for green energy utilization between countries and some obstacles to be removed to promote the energy interconnection projects from technical, economic, marketable, and energy security standpoints. Especially, energy security in terms of politics, as well as vulnerability characteristics of renewable energy, could cause the interconnected system blackouts. These could be a serious obstacle to realization and continuous stable operation of these interconnection projects. Finally, this paper will specify the future directions and possible scenarios for power system interconnection by integrating these issues comprehensively from Korea's perspective.
\end{abstract}

Index Terms: power system, interconnection, Northeast Asia, energy policy, international energy cooperation.

\footnotetext{
${ }^{*}$ Corresponding author.

E-mail: ysa1624@keri.re.kr
}

http://dx.doi.org/10.38028/esr.2020.04.0006

Received September 18, 2020. Revised September 29, 2020.

Accepted October 11, 2020. Available online February 01, 2021.

This is an open access article under a Creative Commons Attribution-NonCommercial 4.0 International License.

C) 2020 ESI SB RAS and authors. All rights reserved.

\section{INTRODUCTION}

This paper deals with the future directions and potentials of power system interconnection between NEA countries from Korea's perspective. These will include the prospects for the Korean power industry, $\mathrm{CO}_{2}$ emission reduction target, and existing power interconnection scenarios for the promotion of power system interconnection. Many institutes have published the power system interconnection scenarios since 2000 , and these scenarios contain the overall preliminary feasibility results. These existing studies show which methodology could be used to interconnect this complex total system for a specific country. This paper discusses the trading potentials for green energy utilization and some obstacles to be overcome to promote energy interconnection projects in Korea. Especially, energy security in terms of politics, as well as vulnerability characteristics of renewable energy itself, could cause the interconnected power system blackouts. These could be a serious barrier to the promotion, realization, and continuous stable operation of these interconnection projects. This paper will specify the future directions and possible scenarios for power system interconnection by integrating these issues from Korea's perspective.

\section{FUTURE PLAN ON POWER SUPPLY}

This section deals with a plan on the power industry and the potentials of power system interconnection on the Korean side. It focuses on the overview of the power industry, energy supply plan, and energy policy, including the $\mathrm{CO}_{2}$ reduction scheme in Korea.

\section{A. Power Supply Plan in Korea}

According to the 8th power supply and demand plan [1], the total power target demand is expected to reach $589.5 \mathrm{TW} \cdot \mathrm{h}$ in 2030 , and the annual increase rate will be about $1.0 \%$. The target peak load will be expected to reach $100.5 \mathrm{GW}$ in 2030 , and the annual increase rate will be $1.3 \%$. This means that the annual growth rate of power consumption will be expected to be saturated in the near 
Table 1. Target power demand (unit: tw.h/gw)

\begin{tabular}{|c|c|c|c|}
\hline \multirow[t]{2}{*}{ Year } & \multirow[t]{2}{*}{ "Consumer Demand $(\mathrm{TW} \cdot \mathrm{h})$} & \multicolumn{2}{|c|}{ Peak Load (GW) } \\
\hline & & Summer & Winter \\
\hline 2020 & 540.1 & 88.8 & 90.3 \\
\hline 2021 & 548.9 & 90.4 & 92.1 \\
\hline 2022 & 556.1 & 91.5 & 93.3 \\
\hline 2023 & 561.7 & 92.6 & 94.5 \\
\hline 2024 & 566.2 & 93.5 & 95.7 \\
\hline 2025 & 569.8 & 94.4 & 96.7 \\
\hline 2026 & 572.8 & 95.1 & 97.6 \\
\hline 2027 & 575.2 & 95.8 & 98.4 \\
\hline 2028 & 577.0 & 96.4 & 99.1 \\
\hline 2029 & 578.5 & 97.0 & 99.8 \\
\hline 2030 & 589.5 & 97.5 & 100.5 \\
\hline 2031 & 580.4 & 98.0 & 101.1 \\
\hline Annual Increase Rate & $1.0 \%$ & $0.9 \%$ & $1.3 \%$ \\
\hline
\end{tabular}

[Target Demand $(\mathrm{kW} \cdot \mathrm{h})]=[$ Base Demand $(\mathrm{BAU})]-$

$[$ Demand Management $]+[$ Others $(\mathrm{EV})])$

Table 2. Confirmed installed capacity in Korea (as of 2030)

\begin{tabular}{lcccccc}
\hline \hline \multicolumn{1}{c}{ Subjects } & Nuclear & Coal & Renewable & LNG & Others & Sum \\
\hline Effective cap. (GW) & 20.4 & 38.9 & 8.8 & 44.3 & 6.0 & 118.3 \\
\hline Rated cap. (GW) & 20.4 & 39.9 & 58.5 & 44.3 & 6.1 & 169.2 \\
\hline \hline
\end{tabular}

Table 3. RES capacity by type in Korea (as of 2030)

\begin{tabular}{lccccc}
\hline \multicolumn{1}{c}{ Subjects } & PV & Wind & Hydro & Others & Sum \\
\hline Rated Capacity (GW) & 33.53 & 17.674 & 2.105 & 5.152 & 58.461 \\
\hline Peak contribution (\%) & $15.6 \%$ & $1.9 \%$ & $28.1 \%$ & - & $15.4 \%$ \\
\hline Effective Capacity (GW) & 5.231 & 0.336 & 0.591 & 2.614 & 8.772 \\
\hline \hline
\end{tabular}

future. This target demand means the base demand under BAU (Business As Usual) scenario minus the quantity for demand response management plus other affecting factors such as electric cars, and others. The 9th basic power demand and supply national plan will be published soon later within this year, and this forecast may be somewhat different from the above-mentioned values.

Regarding the peak demand periods, currently, we have the double peak demand annually, both summer daytime (early August) and winter midnight (early January) peaks. But, we expect this trend to change to single peak demand (summer daytime peak). This will be described in detail in the next $9^{\text {th }}$ basic electric demand-supply plan.

It is expected that the total rated installed capacity will reach $169.2 \mathrm{GW}$, and the renewable energy capacity will be $58.5 \mathrm{GW}$ in 2030. However, Korea has no sufficient primary energy resources and imports almost $95 \%$ of its primary energy resources. Currently, the Korean power market is undergoing restructuring and experiencing internal turmoil stemming from difficulty acquiring power plant sites and dealing with environmental issues. We have complex issues that involve international cooperation (power system interconnection), power industry restructuring (market reform), $\mathrm{CO}_{2}$ reduction plan, and public acceptance issues related to the construction and operation of power system facilities. To overcome these difficulties, the Korean government is planning an energy policy to expand the renewable energy supply and develop cooperation with neighboring countries. These are the key factors to promote the power system interconnection.

Therefore, the Korean government has the renewable energy extension plan, the so-called 3020 and 4030 policy. The 3020 policy means a renewable generation share will be increased by $20 \%$ of total generation until 2030. Also, this 3020 policy was changed by the 4030 policy, which increases the RES supply target to 35-40\% within 2040. According to these policies, the Korean government has a plan to abolish nuclear and coal-fired generations for the protection of air quality and reduction of $\mathrm{CO}_{2}$ emission. The renewable energy supply will significantly expand to $35-40 \%$ of the total generation $(\mathrm{kW} \cdot \mathrm{h})$ by 2040 . But, the nuclear and coal energy portion will decrease rapidly. This plan contains the baseline demand and the target demand. The baseline demand means the electricity demand under a scenario, in which the current technology development, consumption trend, and energy policy will be continuously maintained.

The installed effective generation capacity will reach $118.3 \mathrm{GW}$ in 2030 . We can see that the renewable energy sources will increase very rapidly from $11.3 \mathrm{GW}$ in 2017 to $58.5 \mathrm{GW}$ in 2030 . These $58.5 \mathrm{GW}$ of renewable energy resources include $33.5 \mathrm{GW}$ of solar sources and $17.7 \mathrm{GW}$ 
Table 4. Renewable energy share by year in Korea

\begin{tabular}{lllll}
\hline \hline & 2022 & 2026 & 2030 & 2031 \\
\hline Generation Amounts (TW·h) & $58.3(9.6 \%)$ & $89.5(14.4 \%)$ & $125.8(20.0 \%)$ & $126.0(19.9 \%)$ \\
\hline Capacity (GW) & $23.3(16.4 \%)$ & $38.8(25.4 \%)$ & $58.5(33.7 \%)$ & $58.6(33.6 \%)$ \\
\hline \hline
\end{tabular}

Table 5. CO2 emission target before NDC submission

\begin{tabular}{lll}
\hline \multicolumn{1}{c}{ Subject } & \multicolumn{1}{c}{$\mathrm{CO}_{2}$ Target } & \multicolumn{1}{c}{ Remarks } \\
\hline Total & $\begin{array}{l}574.3 \mathrm{Mtons} \\
(608.4-34.1)\end{array}$ & Including 34.1 Mtons for additional reduction potential of transition sector \\
\hline Total (2030) & $\begin{array}{l}536.0 \mathrm{Mtons} \\
(574.3-38.3)\end{array}$ & 38.3 Mtons reduction by importing or forest resources absorption \\
\hline Transition sector target & $\begin{array}{l}192.7 \mathrm{Mtons} \\
(333.2-140.5)\end{array}$ & $\begin{array}{l}\text { Prospective amounts equal to 333.2 Mtons, } \\
\text { Reduction quantity of 140.5 Mtons (42.2\%) }\end{array}$ \\
\hline \hline
\end{tabular}

of wind sources. These two types of sources account for $88 \%$ of total renewable capacity. The gas generation plants also increase from $37.4 \mathrm{GW}$ in 2017 to $44.3 \mathrm{GW}$ in 2030. However, the nuclear power plants will decrease from $22.5 \mathrm{GW}$ in 2017 to $20.4 \mathrm{GW}$ in 2030 . Even though the renewable capacity will increase to $58.5 \mathrm{GW}$ based on total rated capacity, the effective rating is only $8.8 \mathrm{GW}$ considering the practical capacity factor of RES [2].

As already mentioned, the renewable generation share by year is described and will reach $20 \%$ of the total power generation in 2030.

\section{B. $\mathrm{CO}_{2}$ Reduction Plan in Korea}

According to the $8^{\text {th }}$ base power demand and supply plan, the power generation sector accounts for one-third of $\mathrm{CO}_{2}$ emission, around $34 \%$ or more, and is the key factor for the national $\mathrm{CO}_{2}$ reduction plan under the Paris agreement. The average emission quantity per unit generation $(\mathrm{kW} \cdot \mathrm{h})$ is around $0.459 \mathrm{tCO}_{2} / \mathrm{MW} \cdot \mathrm{h}$ now, but, in the future, this value will go down gradually because of the increase in renewable energy resources. The total $\mathrm{CO}_{2}$ emission target is 536 Mtons, including the additional reduction potential of the transition sector and reduction in imports in 2030. This is a $37 \%$ reduction target for the existing BAU scenario and a $22.3 \%$ lower value than in 2015 . The transition sector target accounts for 192.7 Mtons in total national emission quantity, and, as a result, the reduction amount for the transition sector is 140.5 million tons $(42.2 \%$ of the transition sector original emission quantity equal to 333.2 million tons). In addition to this transition sector target, we will have the additional reduction potential of 34.1 Mtons through the renewable energy transition $\left(6.4 \%\right.$ of total $\mathrm{CO}_{2}$ emission target of 536 Mtons). The final emission target will be confirmed before the submission of NDC in 2020 . Therefore, this target could change. The $\mathrm{CO}_{2}$ market is now operating, and the trading charge of $\mathrm{CO}_{2}$ is changed from time to time. But, according to the IEA base projection for $\mathrm{CO}_{2}$ emission, $\mathrm{CO}_{2}$ cost is estimated at $\$ 10-30 / \mathrm{tCO}_{2} \mathrm{e}$. This $\mathrm{CO}_{2}$ cost could be a promotion factor for the power system interconnection in NEA

\section{EXPECTED SCENARIOS ON POWER SYSTEM INTERCONNECTION}

\section{A. Importing Capability of Korea}

As mentioned above, the peak demand of Korea in 2030 will be expected to reach $100.5 \mathrm{GW}$. Given energy security from a general standpoint, the maximum interconnection

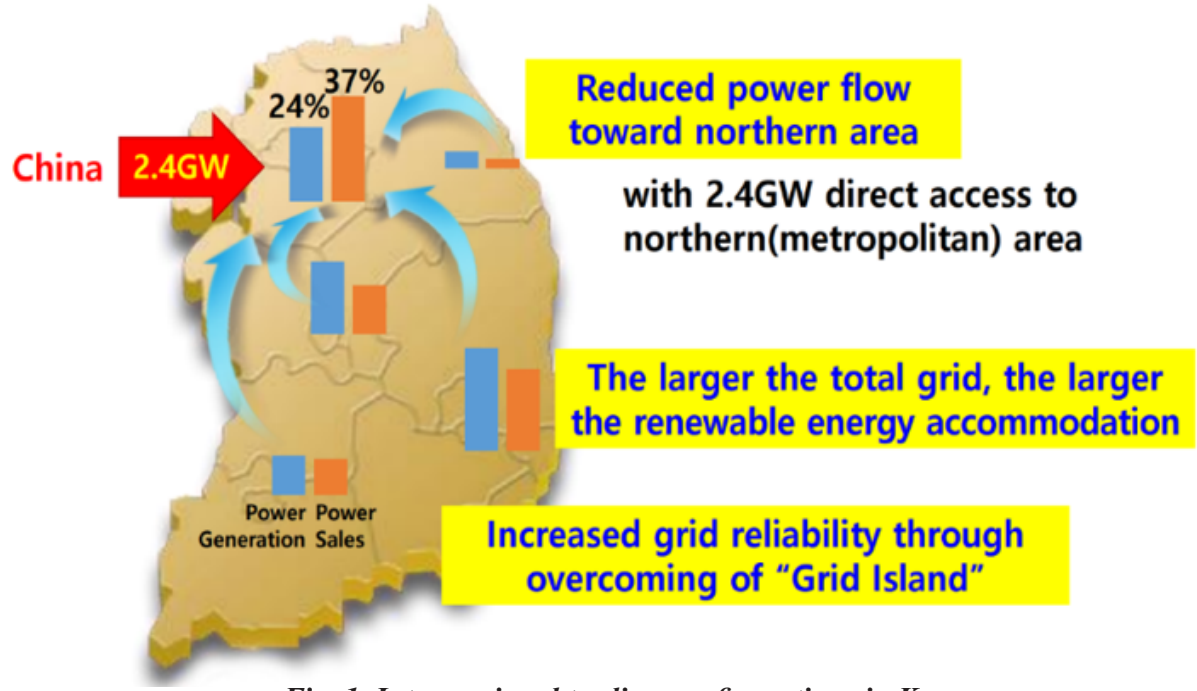

Fig. 1. Intra-regional trading configurations in Korea. 


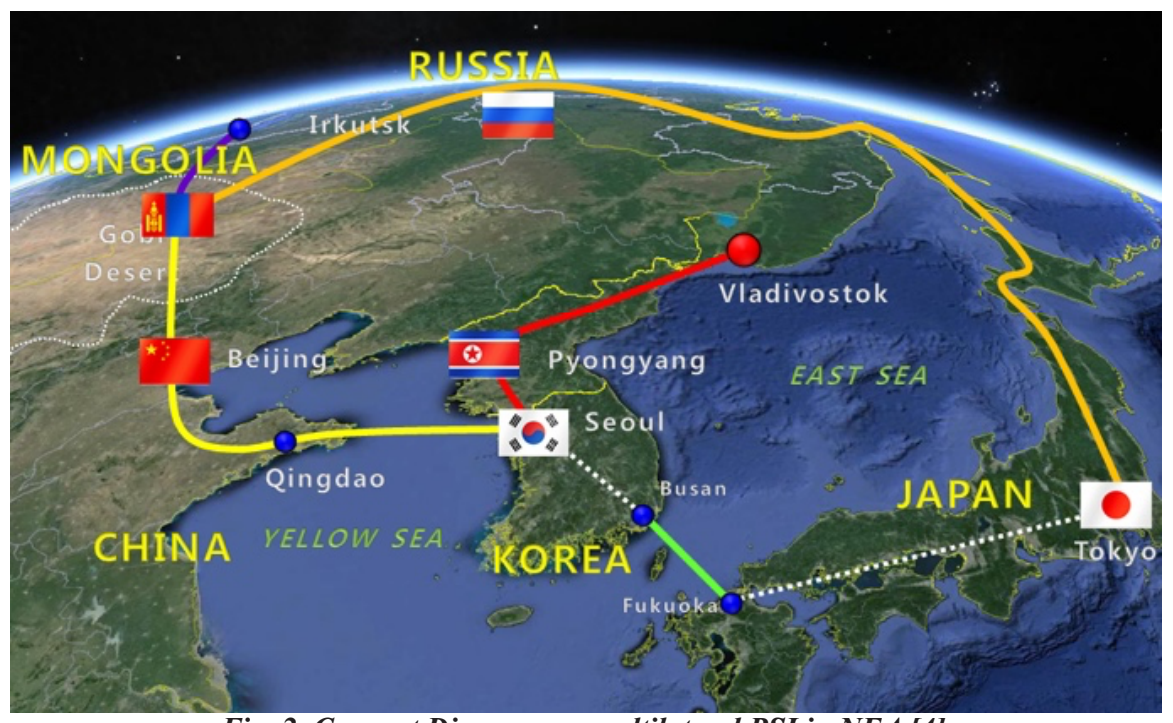

Fig. 2. Concept Diagram on multilateral PSI in NEA [4].

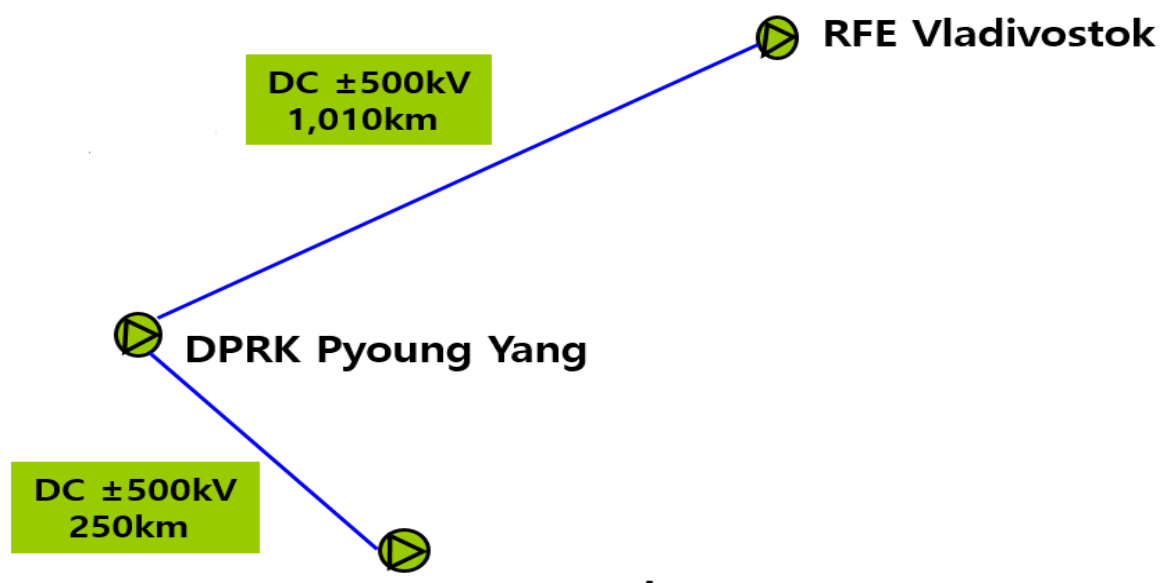

ROK Seoul

Fig. 3. A scenario of interconnection between Korea and Russia through DPRK [5].

capacity is less than $5 \%$ of the peak demand. Therefore, the maximum importing capability of Korea from all countries is supposed to be less than $5 \mathrm{GW}$ in 2030. In general, the blackouts in the power network have a huge social, economic and political impact. If the power resources are diversified, the total supply cost increases, but power supply reliability improves. This is because even if a failure occurs in one power source, the remaining power sources operate normally. The same concept also applies to power system interconnection between countries. For importing countries, if they have only one import transmission line, it is very dangerous from an energy security perspective. This means the maximum interconnection capacity from one country, one point to Korea, must be limited to as much as or lower than $3 \mathrm{GW}$.

In addition to the power system interconnection promotion, our Korean power system has some transmission restrictions from the eastern and southern generation sites to the northern load center nearby the Seoul metropolitan area. If we have the interconnector with neighboring countries, these transmission restrictions can be mitigated.
We could also solve the $\mathrm{CO}_{2}$ reduction and the serious dust (PM2.5, PM10) problems if we import renewable energy.

Regarding the interconnection project, we have common issues in terms of system interconnection and market integration. These can be divided into specific categories, technical, economic, and market integration issues. These issues could be the obstacles to be overcome for power trading in NEA.

[Technical] Transmission planning \& operation

- Conclude an agreement for planning, construction, and operation of cross-border interconnected power system.

- Harmonize the interconnected system reliability standards.

Avoid the vulnerability by importing the renewable energy.

\section{[Economic/Environmental]}

- Pricing and Trading Method: Fixed or Negotiated in steady-state and emergency conditions.

- Creation of Greenmarket (Power and $\mathrm{CO}_{2}$ trading).

[Market Integration] 


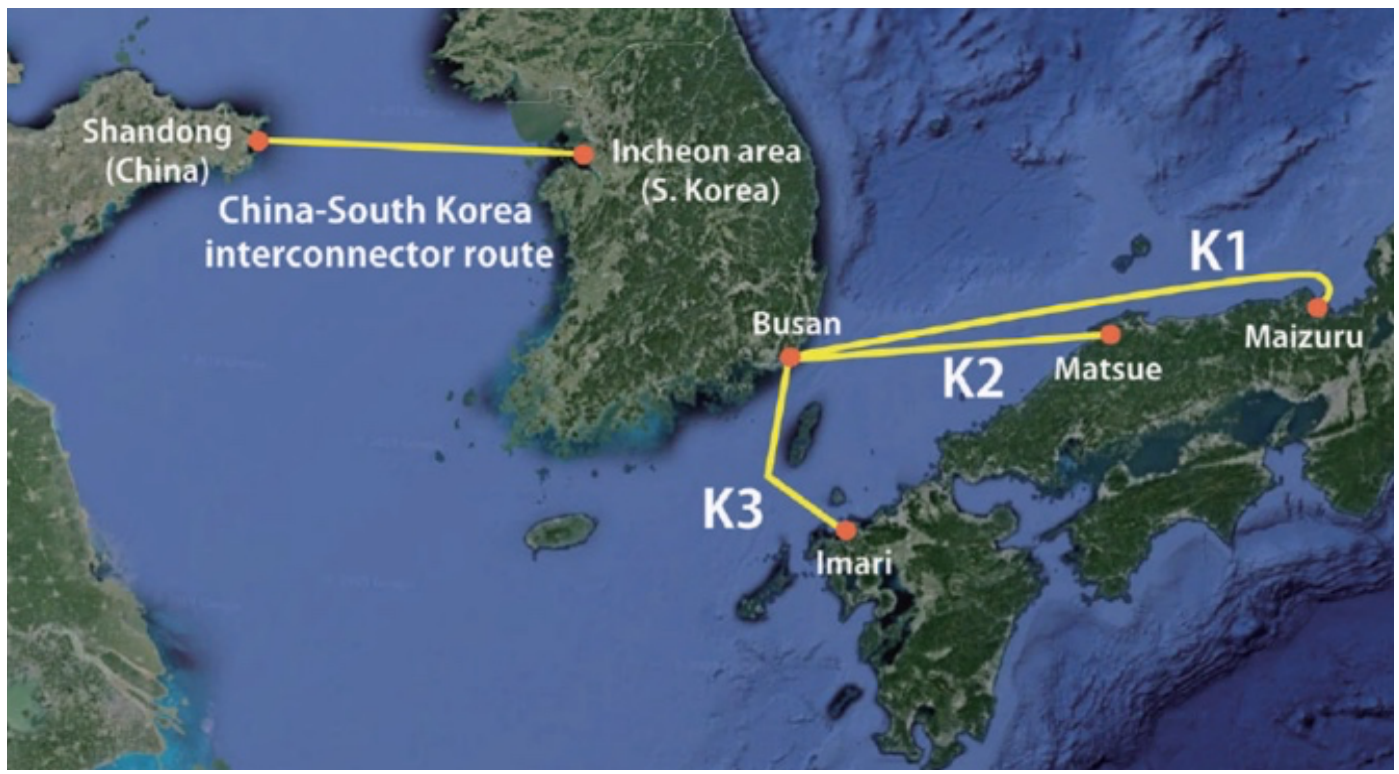

Fig. 4. Scenario of interconnection between Korea, China, and Japan

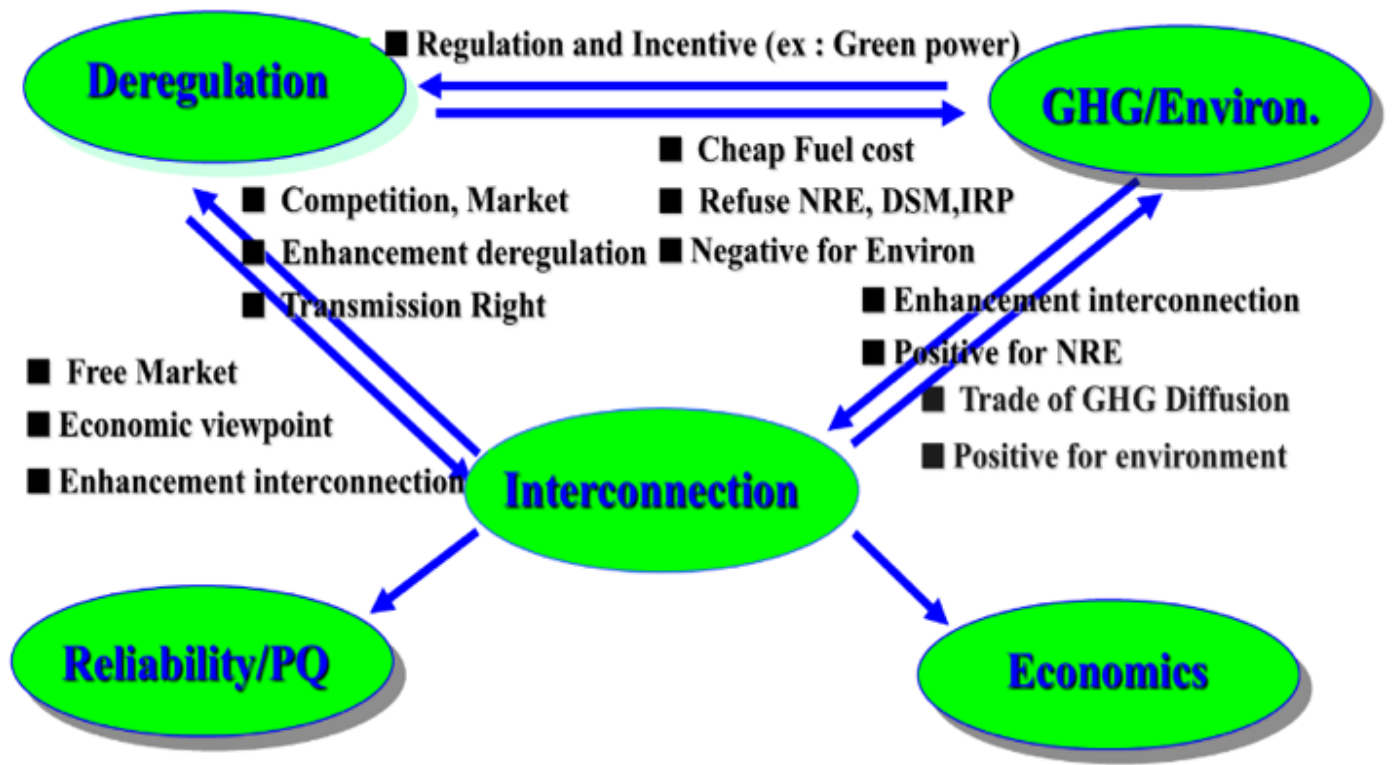

Fig. 5. PSI and other related issues.

- Integrated power market creation \& Correlation with energy market deregulation and other issues.

- Institutional consideration: Need for a change in power market legislation of each country.

[Financing, Political and Energy Security]

- Investment financing and cost recovery method.

- Countermeasures for energy security in a political sense.

\section{B. Interconnection Scenarios}

Korea has power system interconnection plans with neighboring countries, including China, Russia, and Japan. Many scenarios on power system interconnection between Korea and neighboring countries (Russia, China, Japan, and Mongolia) have been studied since 2000. Many institutes have published various reports on the potential, possibility, and preliminary feasibility study results. They included various contents for the realization of power system interconnection with corresponding countries and pointed out some issues to be solved on a bilateral or multilateral basis [3]. However, all of these study results are outdated, and, hence, they should be revised in the near future.

NEA-CBT reports since 2000 (Multilateral PSI)

- NEAREST (KERI and ESI 2003)

- Asian Super Grid (JREF 2011)

- GOBITEC (ECS 2014)

- Northeast Asia Supergrid (KEPCO, KEEI with Skoltech, 2014)

- GRENATEC (HRENATEC 2010)

- Asia Pacific Power Grid (Japan Policy Council 2011) 


\section{Bilateral PSI Scenarios}

- Korea-China, Korea-Japan, Korea-Russia, KoreaDPRK in Korea perspectives

- China-Russia, Russia-Japan ...

The above reports have a somewhat similar or different concept and contents from a technical, economic, and marketable viewpoint with each other. Among these studies, the study for GOBITEC, which focuses on the renewable energy development in GOBI desert and interconnection with importing countries, is the best alternative for crossborder green power trading. This GOBITEC produced power could be transmitted to neighboring countries like Russia, China, Korea, and Japan. In addition to GOBITEC, we would utilize the Russian hydro potential, and this will be a good candidate for the power system interconnection. Relying on this concept, we could consider the overall power system interconnection concept around NEA countries. This will be the whole power system interconnection scenarios based on a multilateral economic and political agreement. However, now, the bilateral power system interconnection concept is more popular and welldeveloped than multilateral trading.

Regarding the bilateral interconnection, at first, power system interconnection between Korea and Russia through DPRK has been studied and discussed at a private and governmental level since 2000. The feasibility study was also performed jointly by Korean and Russian institutes, which established some interconnection scenarios. But, owing to the DPRK territory, transit and complicated political situations, this plan is still in progress. Secondly, the interconnection plan between Korea and China is now under consideration between KEPCO (Korea Electric Power Corporation) and SGCC (State Grid Corporation of China). This interconnection plan has a capacity of $23 \mathrm{GW}$ and annual power trading of around $20 \mathrm{TW} \cdot \mathrm{h}$. This interconnection plan will be implemented by a submarine cable, and the converter station will be located at nearby Weihai (China) and Incheon (Korea). Also, power system interconnection between Korea and Japan is now under processing, but this is only a private level discussion and faces some barriers. Softbank, as a private company, is only interested in this interconnection plan. We may expect this interconnection plan to take a somewhat longer time than other projects because of quite complex problems.

\section{FUTURE DIRECTIONS}

The final goal of power system interconnection and market integration is to enhance technical reliability, economic efficiency, and regional peaceful relations. This impact induces the generation mix change and an increase in the renewable energy supply. Cross-border interconnector usually diversifies, harmonizes and optimizes the total generation mix because it maximizes renewable energy resources. CDM (Clean Development Mechanism) project could be applied to new developed renewable resources. Generally, power system interconnection may impact other power industry issues. It is strongly related to the energy industry deregulation, and a generation mix change due to environmental issues. All of these aspects have some interrelated positive or negative factors. We believe the power system interconnection will give us the net additional positive effects.

From Korea's viewpoint, we have some complex energy issues that involve international power cooperation with NEA countries, including DPRK, and national $\mathrm{CO}_{2}$ reduction problem under the Paris agreement. To solve these problems, the Korean government is planning an energy policy to expand the renewable energy supply and power system interconnection with neighboring countries. Therefore, the Korean government expects to import eco-friendly energy related to the $\mathrm{CO}_{2}$ reduction plan and expand the renewable energy, so-called 3020 and 4030 policies. These are the major factors to promote the power system interconnection from Korea's viewpoint.

From a geopolitical standpoint, Korean Peninsula is the central area of Northeast Asia's power system interconnection. South Korea is also planning a power system interconnection with neighboring countries. However, there are various political, economic, and technological obstacles, and we will try to overcome them in the future. We all think that this grand project will be a physical power network and a regional peaceful corridor. Therefore, we may expect this project will be realized within the near future through the multilateral political and business agreements despite the significant obstacles it faces.

\section{REFERENCES}

[1] MOIST, " 8 th Power Supply and Demand Plan," 2017

[2] Korean government " 3 RD renewable energy plan," 2018

[3] J. YOON, "Power System Interconnection in NEA," KERI, 2014.

[4] "Power system interconnection in Korea's perspectives," KERI, 2017

[5] "Feasible power exchange model Between the ROK, the DPRK, and Russia," IEEE GM, 2011

Academic SVs and photos were not submitted with the manuscript 